\title{
Kearns-Sayre Syndrome: A Rare Mitochondrial Deletion Disorder
}

\author{
Roy $\mathrm{B}^{1}$, Mondal $\mathrm{G}^{2}$, Nanda $\mathrm{D}^{3}$, Das $\mathrm{S}^{4}$, Das $\mathrm{MK}^{5}$ \\ ${ }^{1}$ Dr. Banasree Roy, MBBS, D.C.H, MD, R.M.O cum \\ Clinical Tutor, Dr. B.C. Roy Postgraduate Institute \\ of Paediatric Sciences, Kolkata, West Bengal, India, \\ ${ }^{2}$ Dr. Gobinda Mondal, MBBS, MD. Assistant Professor, \\ Department of Paediatric Medicine, Burdwan Medical \\ College, West Bengal, India, ${ }^{3} \mathrm{Dr}$. Debojyoti Nanda, \\ MBBS, MS Ophthalmology, RMO cum Clinical Tutor, Dr. \\ BC Roy Postgraduate Institute of Paediatric Sciences, \\ Kolkata,West Bengal, India, ${ }^{4}$ Dr. Somnath Das, MBBS, \\ $\mathrm{DCH}$, Post graduate student in Community Medicine \\ at Institute of Hygiene, Kolkata, West Bengal, India, \\ ${ }^{5}$ Dr. Mrinal Kanti Das. MBBS, MD Paediatrics, Professor \\ and Head, Department of Paediatric Medicine, Dr. \\ B.C.Roy Postgraduate Institute of Paediatric Sciences, \\ Kolkata, W.B., India. At present Professor, Department \\ of Paediatric Medicine IPGMER, Kolkata.
}

\section{Introduction}

$\mathrm{T}$ riad of chronic progressive external ophthalmoplegia (CPEO), bilateral pigmentary retinopathy, and cardiac conduction abnormalities was first described in a case report of two patients in 1958 by Thomas P. Kearns, M.D., and George Pomeroy Sayre, M.D¹.

In 1988, the first connection was made between Kearns-Sayre Syndrome (KSS) and large-scale deletions of muscle mitochondrial DNA (mtDNA)2. KSS occurs spontaneously in the majority of cases. In some cases it has been shown to be inherited through mitochondrial, autosomal dominant or autosomal recessive inheritance. It's a rare disease. The prevalence is estimated between 1and $3 / 100000$. We like to report a child with KSS.

\section{The Case}

A 9 year, Hindu girl, born of non-consanguineous marriage presented with gradually increasing bilateral drooping of upper eyelids (Figure-1) and bilateral hearing loss for the last 4 years. Eyelids drooping had no diurnal variation. Hearing loss was not associated with otorrhoea. Neither there was any history of fever,

\begin{abstract}
A 9 yr girl presented with bilateral ptosis and deafness of gradual onset for the last four years. Associated ophthalmoplegia and pigmentary retinopathy, heart block, raised CSF protein and serum lactate was suggestive of the diagnosis of Kearns-Sayre syndrome (KSS), a rare entity in the spectrum of the mitochondrial deletion syndrome. Search for endocrinopathy revealed no abnormality.
\end{abstract}

Key words: Ptosis, ophthalmoplegia, pigmentary retinopathy, KSS, mitochondrial deletion

headache, vomiting, visual impairment, double vision, other muscle weakness, gait disturbance or regression of developmental milestones. Her elder brother and parents were healthy. On clinical examination, she had $16 \mathrm{~kg}$ body weight ( $<3^{\text {rd }}$ centile) and height $128 \mathrm{~cm}$ (between $10^{\text {th }}-25^{\text {th }}$ centile) with normal developmental milestones. Bilateral ptosis and impaired ocular movements in all directions (suggestive of external ophthalmoplegia) was found with bilateral normal pupils. Ophthalmoscopy revealed pigmentary changes mostly in the posterior fundus. Visual acuity was normal. Rest of the Central Nervous System examination and examinations of other systems revealed no abnormality. On laboratory investigations, complete hemogram was normal. ECG showed Right Bundle Branch Block (RBBB) pattern in V3, V4 leads with normal P-R intervals. Chest $\mathrm{X}$-ray and echocardiography were normal. Serum CK (creatine kinase), $\mathrm{K}+, \mathrm{Ca}++$, Alkaline phosphatase, thyroid function tests, blood sugar, urea, creatinine and urinalysis showed no abnormality. Electromyography (EMG) was normal to low amplitude. Repetitive nerve stimulations studies were normal. Nerve Conduction Velocity (NCV) was normal. Visual Evoked Potential (VEP) and Brainstem Auditory Evoked Potential (BAER) study was normal but pure tone audiometry showed bilateral mild sensorineural deafness. MRI brain showed ill defined areas of altered signal intensity hypo intense inT1W1, hyperintense in T2 and FLAIR, hyperintense

\section{How to cite this article ?}

Roy B, Mondal G, Nanda D, Das S, Das MK. Kearns-Sayre Syndrome: A Rare Mitochondrial Deletion Disorder. J Nepal Paediatr Soc 2013;33(1):61-62. 
in DW1 but isointense in ADC in both cerebellar white matter regions. CSF protein $(140 \mathrm{mg} / \mathrm{dl})$ and plasma lactate $(28.6 \mathrm{mg} / \mathrm{dl})$ were elevated. Muscle biopsy was planned but not done due to non-availability of the specific staining (Gomori Trichrome stain) facility to show Ragged red fibres (RRF). PCR determination of mitochondrial DNA mutation was not available in our setting.

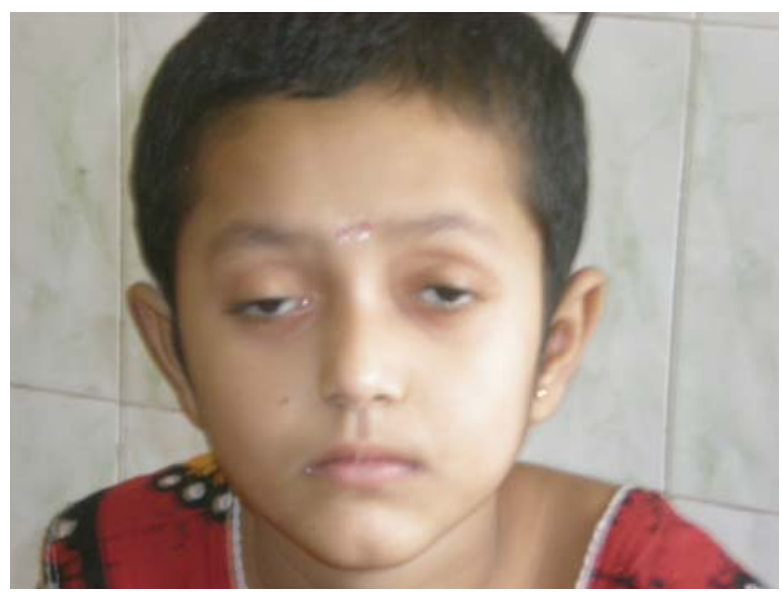

Fig 1: Showing bilateral ptosis in the patient.

\section{Discussion}

Kearns Sayare Syndrome (KSS) is a rare mitochondrial deletion disorder. The criteria for KSS include a triad of: onset before age $20 \mathrm{yr}$, progressive external ophthalmoplegia (PEO) with ptosis, and pigmentary retinopathy. There must also be at least one of the following: heart block, cerebellar syndrome, or cerebrospinal fluid protein $>100 \mathrm{mg} / \mathrm{dl}^{3}$. The said patient had all these features. Other non specific but common features of KSS include dementia, sensorineural hearing loss, and multiple endocrine abnormalities, including short stature, diabetes mellitus, hypothyroidism and hypoparathyroidism. Perceptive deafness was the presentation in our patient but without any feature of endocrinopathy. Serum lactate was found elevated (consistent with KSS) without producing clinical symptomatology. The most important prognostic factor in KSS patients is the involvement of heart ${ }^{1}$, characterized by progressive degeneration of the conducting system. The various ECG abnormalities reported include third degree AV block, complete and incomplete right bundle branch blocks, fascicular blocks, and nonspecific intraventricular conduction delays ${ }^{5}$. In KSS, implantation of pacemaker is advised following the development of significant conduction disease, even in asymptomatic patients ${ }^{1}$. For the presented patient having asymptomatic RBBB pattern, the cardiologist preferred regular ECG monitoring at 3-6 months interval and counseling of parents regarding danger signs of significant conduction disease.
Our patient was treated with advice of appropriate hearing aids, and proper counseling of the parents with emphasis on regular cardiac, ophthalmic, endocrine and auditory check-up. She was advised to avoid drugs potentially toxic to mitochondria, including chloramphenicol, tetracycline, valproic acid, barbiturates, phenothiazines, biguanides, and zidovudine. She was asked to participate in outdoor games as part of regular exercise. Her elder brother was screened and found to be healthy.

\section{Conclusion}

Kearns Sayare Syndrome is an uncommon disease entity. This kind of cases should be reported so that incidence and different types of presentation can be reflected by literature searches. As this is a mitochondrial deletion disorder the chance of affected sibling is $4.11 \%$ but the affected woman has moderate risk that is chance of affected offspring 1 in 24 births $^{7}$. Early detection of disease by screening family member and close relatives will be helpful also genetic counseling is required for them.

\section{References}

1. Kearns TP, Sayre GP. Retinitis pigmentosa, external ophthalmoplegia, and complete heart block : Unusual syndrome with histologic study in one of two cases A.M.A. Archives Ophthalmol 1958;60:280-90.

2. Zeviani $M$, Moraes $C T$, Di Mauro $S$, Nakase $H$, Bonilla E, Schon EA, Rowland LP. Deletions of mitochondrial DNA in Kearns-Sayre syndrome. Neurologia 1988;38:1339-46.

3. Michael VJ. Encephalopathies. In: Kliegman RM, Behrman RE, Jenson HB, Stanton BF., editors. Nelson Textbook of Pediatrics, $18^{\text {th }}$ ed. Philadelphia, Saunders-Elsevier. 2008:2497-98.

4. Young TJ, Shah AK, Lee MH, Hayes DL. KearnsSayre syndrome: A case report and review of cardiovascular complications. Pacing Clinical Electrophysiol 2005;28:454-57.

5. Schwatzkoff BB, Frenzel H, Losse B, Borgreffe M, Toyka KV, et al. Heart involvement in progressive external ophthalmoplegia (Kearns-Sayre syndrome): Electrophysiologic, hemodynamic and morphologic findings. J Cardiol 1986;75:161-69.

6. Gregoratos G, Abrams J, Epstein AE, et al.ACC/ AHA/NASPE 2002 guideline update for implantation of cardiac pacemakers and antiarrhythmia device. Circulation 2002;106:2145.

7. Chinnery $P$ F et al. Risk of developing a mitochondrial DNA deletion disorder. The Lancet 2004;364:592-596. 